THURSDAY, NOVEMBER 26, I885

\section{THE WHOLE DUTY OF A CHEMIST}

$\mathrm{O}^{2}$ the 6 th instant there was a meeting at the rooms of the Chemical Society in the afternoon, and a dinner in the evening, to celebrate the grant of a Royal Charter to an Institute of Chemistry.

The stated object of the Institute is to do for chemists what has been done for the members of different professions and trades by such bodies as the College of Physicians, the College of Surgeons, the old Guilds, and the modern Trades Unions.

This is possibly a very desirable thing to do, but to the student of pure science the creation of the new corporation possesses no other interest than that which results from the consideration of its prospective influence on the progress of science. Indeed the intention is so entirely commercial that we should not have referred to the new body at any length in these columns if the President, Prof. Odling, in an address delivered on the occasion, had not enunciated views which we believe all true men of science will read with pain, and against which we feel it our bounden duty to make a protest.

Before we proceed to deal with the address itself, it will be well to clear the ground by a few general considerations touching the applications of science to industry, and the manner in which, time out of mind, and we hope for all future time, scientific principles have been and will be brought down to be utilised in the ordinary affairs of life. First of all, it will be readily conceded that in the present state of civilisation there is scarcely any handicraft or manufacture or process in which some scientific fact or principle does not lie at the root of the matter. Our boots are the results of scientific applications, our clothes are the result of scientific applications, the materials depend upon science, the fit depends upon science. If one had to define offhand the difference between a profession and a trade requiring skill in making certain articles, one would say that the profession required more science than the trade, that is, there is not a difference of quality, but of quantity. The bootmaker that makes a boot, and the surgeon that cuts off a toe, both deal, if they do their work well, with the anatomy of the foot, but we expect the professional surgeon to know more about this anatomy than the shoemaker. Further, any science in the process of the amalgamation of its applications with other similar amalgamations at first begins by being in the hands of a few individuals, let us say of high training; it becomes generalised, and then finds itself in the hands of a greater number of individuals probably less highly trained, and so on, till each special application of science becomes the common property of the community.

$A u$ fond, then, so far as science is concerned, we can recognise no distinction between a profession and a trade, or we may use the words an industry, if any one likes them better. These industries or professions once started are kept alive and fostered, and made more useful for mankind, by the perpetual introduction of new scientific facts and processes. This is as true for the improvement in leather and cloth manufactures, as it is in the curing of hyarrophobia, which may some day come.

VOL. XXXIII.-No. 839
Chemical science, for example, is the very sap of the chemical industries, and there is the most intimate and the most direct connection between the researcher and the manufacturer. A Reichenbach discovers paraffin, and a Young straightway turns it into candles. Andrews demonstrates the true principles of the condensation of gases, and these principles are forthwith applied to the construction of a freezing-machine. The history of technology teems with instances of this kind. Indeed, some of the huge manufacturing concerns of the Continent are driven to anticipate the output of the purely scientific laboratories of the Universities and higher schools by employing investigators for themselves: the great colour, making manufactory at Ludwigshafen has two score of chemists at work on the industrial development of the chemistry of aromatic compounds. Now these investigators are in the first instance made by the Universities; they are the product of their great chemical schoolsthey are men who have caught something of the spirit of that noble army of teachers who have dedicated their lives to the advancement of natural knowledge for its own sake without thought of guineas or "leading professional position." The growth, then, of the chemical trades must depend ultimately on the help which chemists are able to give to the chemical traders. This help must consist either in new knowledge to be furnished directly by the chemist, or indirectly by the men whom he has so trained that they may know how to seek for it and to find it. Have we not here the true function and real duty of "those of us occupying the leading position in the profession" or "who have already attained the higher steps of the ladder of success," if such men are connected with an University?

The honour given to teachers from the beginning of time was accorded to them not merely for their learning but for the new knowledge they produced and taught. They were the guardians of the sacred fire; and the reverence with which they were regarded depended upon the constancy with which they fed the flame. The estimation in which men of science are held to-day, even if they are not teachers, is due to the national benefits which they confer by giving their lives to learning, teaching, and to writing books for others; and because such men are regarded as the highest benefactors of our race and the founders of our modern civilisation. The nation remembers them even if they often forget themselves.

Such men, however, do not exhaust the number of those who have studied science or who perform useful scientific functions. But the point is, however useful this other class of men may be-like the bootmaker and the tailor, who are eminently useful in their way-their knowledge is merely a stock-in-trade to which they look for their livelihood. We have nothing whatever to say against these men, but it is imperative that we should point out that if their object in life is merely to get money the public estimation of them cannot be expected to be the same as that accorded to those whose lives are devoted to the public good. Is it possible to tell one kind of man from the other?

This can be easily done. Let us assume that he is a professor of science at a well-known seat of learning. Are his lectures the best possible, or does he simply lose the time of his students for so many hours per term? 
Is he the life of his laboratory, always there, always setting an example to his students of patient and continuous research? What is the number of researches produced per annum, and what is their value? Do his students revere him or think little of him? Do they give any indications of benefiting by his instruction? Has he founded a school? Has he impregnated his assistants with the love of new knowledge, and do they spend their time in getting it? Or, again, is he the friend of manufacturers, a grata persona to limited liability companies? Is he a noted expert in our courts of law? Is he never seen in his laboratory? Is the laboratory now silent, its appliances rotting from disuse, and its old reputation for research become merely the shadow of a shade?

It is really quite easy to find out whether this professor of science is doing his duty or neglecting it; whether the getting of knowledge or the getting of money is foremost in his thoughts.

The dignity of a professor in a seat of learning is closely associated with the dignity and the honour of the seat of learning itself. An University which appoints a man to a professorship places its honour in his keeping so far as his science is concerned. Now the members of an University, even though they may not be especially learned in any particular branch of knowledge, soon know, perhaps even by a kind of instinct, whether a professor is upholding the honour of the alma mater in the welfare of which they are all interested; or whether by forsaking the fair fields of knowledge, and by thinking only of self and pelf, he is dragging her reputation through the mire. This feeling in an University affords another criterion which may be safely relied on if we wish to know whether or not a professor is doing his duty.

Take another case. Let it be that of one who is engaged in commercial matters-whether large or small is immaterial to our argument-into which scientific principles and ideas largely enter; or let us assume him to be engaged, on the strength of his scientific attainments, by a Government department or an industrial body which wishes to utilise his knowledge. Does he expand his routine work into an opportunity of enriching science? Does he make himself the recognised master of a large field of knowledge which he gives to the world? Do his labours confer honour on himself or on the body with which he is connected? Or, on the other hand, is his name never heard at a scientific society? does he merely, in short, content himself with the perfunctory performance of the work by which he makes his money?

We have referred to the dignity of a man of science; what does this mean? The view it expresses is simply the modern view representing that feeling of olden time which made teaching so honourable while trade was despised. Then, as now, the man was often foor, but he spent his life in doing a common good, while the trader was often rich, and dispensed his wares for his own advantage. Nowadays the dignity of a leading man of science is somewhat difficult to define exactly, but the same idea lies at the bottom of it. It is known that he cares more for science than for money. It is known that his whole heart is in his researches; even when they happen to be profitable to himself or to others, he is still not a money-grubber. This dignity is not confined to professors, but a man to possess it must be something more than commercial or professional. We cannot imagine a bootmaker or a tailor on the council of the Royal Society, but yet he employs scientific processes to get his money as much as a chemist does who spends his time in commercial analyses or in courts of law. To come back to our criterion, we think we have indicated that there are various ways in which men of science can be allocated in the two classes to which we have referred.

We now proceed to refer specially, and as briefly as we can, to Prof. Odling's address. It begins with a history of the movement, and then goes on to show the everincreasing need there is of "professional services" which are rendered by men of various grades, "from those of us occupying the leading positions in the profession, to the most humble individual practising in our ranks." We are dealing, then, with the chemists employed by Government and large corporations, as well as "experts" and analysts; and among these latter not only with the man of "leading position" who charges ten guineas for analysing a sample of water, but with the assistant who actually does the work for the not excessive sum of half-a-crown.

We next read as follows :--

"It would seem, however, from observations not unfrequently hazarded by some very superior persons, whose happy mission it is to put the rest of the world to rights, that there is something derogatory to the man of science in making his science subservient in any way to the requirements of his fellows, and thereby contributory to his own means for the support of himself and of those depending upon him. Now, on this not uncommon cant of the day a little plain speaking would seem to be very much wanted. While the investigation of nature and the interpretation of natural law are admittedly among the highest, as they are among the most delightful, of human occupations, the right application of natural law to effect desirable objects is in itself a scarcely less worthy occupation ; many of these objects being of paramount importance, and attainable only by the exercise of high scientific sagacity and skill, aided by a fertility of resource and a persistent elasticity of spirit, ready ever to cope with the successive novel difficulties found to be continually opposing themselves."

On this we have to say-and we shall return to the point further on-that we know of no one who has made the abstract proposition which Prof. Odling condemns. We are prepared to say, however, that in the opinion of many who are not men of science, the appearance of a man of science, occupying a "leading position" as an expert in a court of law, whose "devotion" to his employer causes him to apparently contradict the statements of another man of science on the other side, doubtless equally "devoted," does not add to his dignity. A wellknown lawyer, now a judge, once grouped witnesses into three classes; simple liars, damned liars, and experts. He did not mean that the expert uttered things which he knew to be untrue, but that by the emphasis which he laid on certain statements, and by what has been defined as a highly cultivated faculty of evasion, the effect was actually worse than if he had.

It is consoling to think that the qualities most valuable in an expert, since experts there must be, are not those for which men of science are best known. Coolness under cross-examination, verbal dexterity, a ready wit, not too much knowledge or conscience, the fidelity of a partisan, or rather "professional devotion," and a dash of impudence, are quite as frequently the passport to the "professional eminence" of an expert as scientific ability. 
Surely it is not necessary for us to point out the sophistry and fallacy of the argument that "the right application of natural law to effect desirable objects is in itself a scarcely less worthy occupation" than "the investigation of Nature and the interpretation of natural law," when such applications are made at the instigation of an individual-a client-who pays for such application of natural law at the rate of so many guineas a folio; and who, if it suits him, may then proceed incontinently to suppress " the right application of natural law." Are we to elevate such service as this to a high moral platform, and claim for it the same homage or appreciation which is accorded by the outside world to work done unselfishly and for the benefit of the whole community?

Prof. Odling strengthens his view that we should by the following considerations :--

"In this matter, as in so many others, the sense of proportion is but too often lost sight of. Because the investigations of a Newton, a Darwin, a Dalton, a Joule, and a Faraday have an importance of which few among us can adequately conceive even the measurement; because among the scientific men now or but lately living in our midst are to be found those whose investigations in pure science have not only won for them a high renown, but have earned for them the gratitude, and should have obtained for them the substantial acknowledgments, of their country and the world; and because even the minor investigations and discoveries, placed before the world for the world's use, and not merely to enrich a firm, that are ever being made in pure science have all of them their merit and their value, it does not follow that the mere accomplishment, it may be in an abundant leisure, of two or three minor investigations, however creditably conducted, are to lift their authors into a scientific position altogether above that of men whose laborious lives have been spent in rendering their great scientific attainments directly serviceable to the needs of the State and of the community. The accomplishment of such-like investigations does not entitle their authors to claim exemption from the duty of earning their own livelihoods or give them a claim to be endowed by the contributions of others with the means to jog leisurely along, without responsibilities and without anxieties, the far from thorny paths of their own favourite predilection. However heterodox it may be thought by some, the best of all endowments for research is unquestionably that with which the searcher, relying on his own energies, succeeds in endowing himself. The work to which our natures are repugnant, not less than the work which entrances us and hardly makes itself felt as work at all, has to be done. In some degree or other, we have most of us to obtain our own livelihood ; and harsh as may seem the requirement, it will, I suppose, be conceded that the necessity put upon the mass of mankind of having to earn their daily bread is an arrangement of Providence which has on the whole worked fairly well; and, further, that the various arrangements hitherto tried for exempting certain classes of men from the necessity of having to earn their daily bread, in order that they might give themselves up to the higher spiritual or intellectual life, have scarcely, to say the least of them, worked quite so satisfactorily as they were intended to. All of us are, without doubt, qualified for higher things than the mere earning of our daily bread; but the discipline of having to earn our daily bread is, in more ways than one, a very wholesome discipline for the mass of us, and even for the best of us. It may here and there press hardly on particular natures, but it is rarely an impediment to the achievement of the highest things by those having the moral qualities, the judgment, the determination, and the self-denial necessary above everything elise for their achievement. Not a fcw of us may consider ourselves fitted for higher work than the gods provide for us, and fondly imagine what great things we should effect if we could only have our daily bread supplied to us by the exertions and endowments of other less gifted mortals. But experience is not on the whole favourable to the view that, the conditions being provided, the expectation would be realised. Experience, indeed, rather favours the notion that it is primarily the necessity for work, and association with those under a necessity to work,--those in whom a professional spirit has been aroused, and by whom work is held in honour,-that creates and keeps up the taste and the habit of work, whereby the vague ambition to achieve is turned to some productive account. Take, say, a thousand of the most eminent men the world has produced, and making no allowance for the large influence of descent or training, or of association with those to whom work is a necessity, or having been a necessity has become a habit, consider what proportion of these men have, by their means and position in early life, been free from any stimulus or obligation to exert and cultivate their powers; and consider, on the other hand, what proportion of them have been stimulated to exertion and success by the stern necessity of having either to achieve their own careers, or to drop into insignificance, if not indeed into actual or comparative degradation and poverty. We ought, indeed, all of us to be students, and to be above all things students; but the most of us cannot be, nor is it desirable, save in the case of a special few, that we should be only students. We have all our duties to fulfil in this world, and it is not the least of these duties to render ourselves independent of support from others, and able ourselves to afford support to those depending upon us. Fortunate are we in being able to find our means of support in the demand that exists for the applications of a science which has for its cultivators so great a charm. To judge, however, not indeed by their coyness when exposed to the occasional temptation of professional work, but rather by their observations on the career of others, the most sought after and highest in professional repute, the pursuit of professional chemistry is, in the opinion of some among us, a vocation open to the gravest of censure. It is praiseworthy, indeed, for the man of science to contribute to his means of livelihood by the dreary work of conducting examinations in elementary science for all sorts of examining boards, and by teaching elementary science at schools and colleges, and by giving popular expositions of science at public institutions, and by exchanging a minor professorial appointment, affording abundant opportunities for original work, in favour of a more lucrative and exacting appointment involving duties which, if rightly fulfilled, must seriously curtail these same opportunities. It is praiseworthy of him to add to his means by compiling manuals of elementary science, and by writing attractive works on science for the delectation of general readers; but it is, forsooth, derogatory to him, if not indeed a downright prostitution of his science, that he should contribute to his means of livelihood by making his knowledge subservient to the wants of departments, corporations, and individuals, alike of great and small distinction, standing seriously in need of the special scientific services that he is able to render them.

"A glance back suffices to show how foreign to the icleas of the great men who preceded us is this modern notion of any reprehensibility attaching to applied or professional science. In his earlier days, Prof. Faraday was largely employed in connection with all sorts of practical questions, and until almost the close of his life, continued to act as scientific adviser to the Trinity House. No man was more constantly occupied in advising with regard to manufacturing and metallurgic and fiscal questions than Prof. Graham, who ended his days holding the 
official position of Master of the Mint; a position in which he succeeded another eminent man of science, less known, however, as a chemist than as an astronomer, Sir John Herschel. . . .

"So far, moreover, from his professional eminence and usefulness being made a matter of reproach to the scientific man, it should constitute rightly a claim to his higher consideration ; and far from being accounted a disparagement, should be held as an addition to his scientific standing. In the professions most allied to our own on the one side and on the other this is well recognised. The physician and the engineer are not merely students of pathology and of mechanics, however important may have been their contributions to pathology and mechanics respectively, but they are the distinguished craftsmen in their respective arts. And whether or not they may have made important contributions to pure science, their rank as eminent scientific men is everywhere and rightly conceded to them. A lucky chance happening to any professional man may indeed bring him to the front, but no succession of lucky chances can ever happen that will of themselves prove adequate to keeping him there. Great qualities are ever necessary to sustain great professional positions; and to be for years one of the foremost in a scientific profession is of itself at least as substantial an evidence of scientific attainment as is the publication of a memoir on some minute point, say of anatomy, or chemistry, or hydrodynamics, for example. And it is so recognised, and very properly recognised, even in quarters where pure science admittedly reigns supreme. Leading engineers and leading physicians and surgeons are every year admitted into the Royal Society, not on account of the importance attaching to any special contributions they may have made to mechanical or pathological science, but mainly because of their eminence in their several professions, in which to be eminent is of itself an evidence of scientific character and of extensive scientific knowledge. It may indeed be taken as beyond question that to obtain and retain a leading position in a scientific profession, needs among other things the possession of high scientific attainments. I say among other things, for without moral qualities in a notable degree, sympathy, endurance, courage, judgment, and good faith, no such professional success is conceivable. Professional eminence is the expression necessarily of scientific ability, but not of scientific ability alone. The self-engrossing science of the student has to be humanised by its association with the cares and wants, and the disappoint ments and successes of an outside world."

Having given this long extract from the address, we now proceed to remark on certain parts of it.

In the whole of Prof. Odling's references to the endowment of research, which was so warmly advocated by his predecessor at Oxford, Sir Benjamin Brodie, there is much evidence that he has not even begun to understand the question. No one has ever proposed to endow research for the benefit of the researcher, or to endow researches which are immediately remunerative. The highest needs of the nation and of learning have been alone considered. The idea of endowment was only suggested for the encouragement of such researches as promised no immediate return in the shape of utility, except as pure knowledge. Prof. Odling seems to imagine that if the Fellowships of an University were awarded to men of eminence in science or who had given proof of skill in research, the Fellows would be but charity-boys of larger growth. When Prof. Huxley told the Americans that any country would find it greatly to its profit to spend 100,000 dollars in first finding a Faraday, and then putting him $i_{n}$ a position in which he could do the greatest possible amount of work, he was not thinking that Faraday would thus be enabled to give nice dinners, but of the results of that greatest possible amount of work-the new knowledge that would be certain to be garnered and utilised some day for the nation's good. The endowment of research, or aid to research in any form, seerns to be so objectionable to the President of the Institute, that the winding up of the Research Fund of the Chemical Society would seem to be one of the most desirable things of the present time, if his opinion is to prevail.

Prof. Odling employs in his argument a well-known method of procedure often used to throw dust in the eyes of a jury. He has put up a bogus case in order to demolish it very much to his own satisfaction. We fear that in this process he has been guilty of much, doubtless unconscious, misrepresentation of many revered names in science. This dummy is the assumed opinion of men of science that a man of science should do nothing to help industry directly. This opinion, as we have before stated, nowhere exists. The opinion does exist, as we have already implied, that such assistance must not interfere with higher work if higher work has been undertaken; and the general consideration of the man of science has risen enormously when it has been known that such aid, when given, has been given openly to allcomers, and not in secret to him who could pay the highest fee. Prof. Odling, in apparent justification of his case, quotes, amongst others, the names of Faraday and Graham, and states roundly that they have done the thing to which the superior persons to whom he refers object. This is untrue; no men were more faithful to their trust than Faraday and Graham, and the proof of our contention lies in the fact that their names are honoured among us while others, their contemporaries, the Ures and Lardners of that day, although men of tremendous "professional eminence," are already forgotten, or live only in the pages of a Thackeray. It has been stated over and over again that such was the fidelity of Faraday to his trust that he refused sums which would have amounted in the aggregate to a large fortune which were offered to him by manufacturers and others to tempt him to neglect his public work for their private advantage. It was a subject of pride to him that he had refused pay for all work he had done for the Government except on one occasion when he accepted it for the sake of a coadjutor. The volumes of Faraday's and of Graham's researches, not to mention those of other honoured names, representing their fidelity to pure investigation during the whole of their working lives, are, after all, the best answers to Prof. Odling, and when we contrast their faithful and longcontinued activity in this direction with that of others which began with almost as fair a promise, and then suddenly, before the men were in their prime, was seized by a paralysis or else diverted into other channels, we have an indication, by no means to be despised, of the possible result of merely commercial work.

We believe that some chemists, although they hold the views which we express in this article, have allowed their names to be connected with the new institution, because they think that it may eventually, somehow or other, aid chemical education in this country. We think that this is an error. The College of Physicians has been pointed out as a precedent for the Chemical Institute. Now what 
has the College of Physicians done for medicine and for medical education? Although it was one of the first founded of the Professional Guilds, we have had repeated occasion to point out in these columns that in the opinion of the most competent authorities, medical education even to-day is the worst organised and least effective.

The latter part of the extract gives Prof. Odling's view as to the easy admission afforded by professional eminence into the Royal Society. As regards engineers, we have never heard of any one being elected into the Royal Society except on the ground of his contributions to science. Commercial or professional eminence has, so far as we know, not been considered. As regards doctors, owing to the ancient ties of the Royal Society with medicine, we believe that it has been the custom to consider, in judging their claims, that marked eminence in their profession should be taken into account; but professional eminence alone does not decide the choice. In saying this we do not express our own opinion merely ; and we must add that there is no written law in the matter, the decisions each year resting with the Council of that year, and the Council, as is known, is an everchanging body.

The latter part of Prof. Odling s address, which we have not space to give at length, deals with the advantages which in his opinion are likely to result from the new organisation. He also gives some paragraphs from the preamble of the charter under which the Institute has now been incorporated. One of these paragraphs runs as follows:- " That the said Institute was not established for the purposes of gain, nor do the members thereof derive or seek any pecuniary profits from their membership." We confess we find it difficult to harmonise this extract from the charter with the general drift of the part of the address now under consideration; for although Prof. Odling frankly acknowledges, to quote his words, "to those of us who have already attained the higher steps on the ladder of success it can scarcely afford any personal advantages whatever," it is clear that this is not to obtain universally. Among the "advantages" we find not only "gain to the public" but "gain to ourselves"; we read of "noteworthy advantages, social and material, to the persons" who form the Institute. We also read: "Among its other objects, the Institute of Chemistry exists undoubtedly for the purpose of improving the position and prospects of professional chemists"; we further find that the Institute "will add alike to the social and substantial attractiveness of the chemical profession."

We do not find too many references to researches not of a directly remunerative kind, but Prof. Odling makes one concession: he thinks that among the members of the Institute "some proportion, at any rate, will find the pursuit of research the vocation for which they are especially qualified, and for which they will, IN THE SEEDSOWING TIME OF THEIR LIFE, be willing to make, as others have made before them, even considerable professional sacrifices."

Ilias in muce. In the phrase we have put into capitals we have the real key to the address. It would appear that the life of a chemist should be divided into two periods-Seed-time and Harvest. Research may be the seed, the harvest must be gold. The continued pursuit of truth, the continued love of science for its own sake, may be left to the unwise. The ideal chemist is one who uses research only as an investment. He carefully limits it to his earliest years. By it he is to gain a reputation as a man of science. His reputation thus gained procures for him a post of high scientific honour and position. The "seed-sowing time" is now over. The golden harvest is ripe. It has to be reaped and garnered. The duties of the position of honour obtained by the original investment are therefore to be thrown to the winds in order that this may be done. He is now a man of "professional eminence": he is now on "the higher steps of the ladder of success."

Does any one think that his electors have a right to protest or his friends to lament? Certainly not; they have no such right. Their feelings have simply arisen from their ignorance of the Whole Duty of a chemical Man.

In these days of rapid intercommunication among nations we know that Prof. Odling's address will be carried to our brethren beyond the seas and to many centres of scientific activity in other lands. We wish it to be known, therefore, that the spirit it breathes is an alien spirit, repugnant to students of pure science in this country.

CENTKAL AMERICAN COLEOPTERA

Biologia Centrali-Americana. Insecta: Colcoptera. Vol. I. Part I. By H. W. Bates. (London: R. H. Porter, I $88 \mathrm{I}-84$.)

THIS part of Godman and Salvin's great work is now complete, and though called a part is practically a volume, with introduction, indices, and completed pagination; its publication has extended over four years. It deals with the two great families of carnivorous beetlesthe Cicindelidæ and Carabidæ-and consists of 316 pages of letterpress and thirteen plates of coloured figures. The number of species of the two families recorded from the region is 1086 , belonging to 154 genera. Nine new genera and about 450 new species are described, this latter figure including, however, a certain number of species characterised for the purposes of this work in the Proceedings of the Zoological Society for 1878 and a few others similarly dealt with in the Annals and Magazine of Natural History. In his introduction the author touches on some points of geographical distribution, and states that the inclusion of the central highlands of Mexico and Guatemala in the Nearctic province by Wallace is not supported by these insects, but that on the contrary they markedly confirm the essentially Neotropical character of the Central American fauna. $\mathrm{He}$ also is inclined to adopt the opinion that the Central American region comprises two distinct sub-provinces, as proposed by Salvin from his study of the birds, the line of division passing probably across Nicaragua ; and considers that even the more northern of these sub-provinces is not a southern extension of the Nearctic province, but rather a remarkably distinct sub-province of the Neotropical fauna.

In the body of the work the distribution and extent of each genus is briefly stated, and, so far as known, every 